\title{
Measurement and analysis of green water resources efficiency in Jing-Jin-Ji
}

\author{
XieHeng ${ }^{1}$ \\ ${ }^{1}$ School of management of Tianjin University of Technology, research center for circular economy and sustainable development of \\ enterprises, Tianjin 300384
}

\begin{abstract}
Jing-Jin-Ji as one of the most serious water shortage areas in China, improving the green efficiency of water resources is the only way to solve the contradiction between supply and demand of water resources and realize the harmonious development of economy, society and ecology. Based on the Super-SBM model and geographical detector model, this paper measures the green water resources efficiency of Jing-Jin-Ji from 2008 to 2018, and analyzes the spatial and temporal differentiation. The result shows that:The efficiency of green water resources in Jing-Jin-Ji fluctuates in an unstable state, and does not reach the DEA effective state, and there is a big gap between the maximum and minimum efficiency of urban agglomeration.
\end{abstract}

\section{Introduction}

As the basis of maintaining life and health, freshwater resources are indispensable natural resources for human survival and development. However, the research shows that there are about 1.5 billion people in more than 80 countries in the world facing the shortage of fresh water, and the problem of water resources has become a major strategic issue related to national economic and social sustainable development and long-term stability. The core of water resources utilization is efficiency. Improving water resources utilization efficiency, especially green water resources efficiency, is the only way to fundamentally solve the contradiction between supply and demand of water resources and realize the harmonious development of economy, society and ecological environment.As one of the three major urban agglomerations in China, Jing-Jin-Ji is an important engine of China's economic development. The per capita water resources is only $9.14 \%$ of the national per capita level, and the uneven distribution of water resources and water pollution are serious. It is one of the regions with the most serious shortage of water resources in China. The lack of water resources has become the biggest "short board" in the development of Jing-Jin-Ji ${ }^{[1]}$. In this context, it is of guiding significance to study the efficiency of green water resources in Jing-Jin-Ji and implement the concept of green development to promote the integration process of Jing-Jin-Ji and the green development of regional economy.

\section{Data and methods}

\subsection{Super efficiency SBM model}

Selecting super SBM model based on unexpected output as the evaluation model of Beijing Tianjin Hebei Urban green water resources efficiency can not only effectively avoid the error caused by the traditional DEA model only considering the radial relationship, but also further compare the effective decision-making units, which is more conducive to the accuracy of the calculation results. Based on this, the green innovation efficiency evaluation model is constructed as follows:

$$
\begin{aligned}
& \text { Min } \rho=\frac{1+\frac{1}{m} \sum_{i=1}^{m} \frac{s_{i}^{-}}{x_{i k}}}{1-\frac{1}{t_{1}+t_{2}}\left(\sum_{t=1}^{t_{1}} \frac{s_{t}^{g^{+}}}{y_{t k}^{g}}+\sum_{t=1}^{t_{2}} \frac{s_{t}^{b^{-}}}{y_{t k}^{b}}\right)} \\
& \text { S.t. }\left\{\begin{array}{l}
\sum_{j=1, j \neq k}^{n} x_{i j} \lambda_{j}-s_{i}^{-} \leq x_{i k} \\
\sum_{j=1, j \neq k}^{n} y_{t j} \lambda_{j}+s_{t}^{\mathrm{g}^{+}} \geq y_{t k}^{g} \\
\sum_{j=1, j \neq k}^{n} y_{t j}^{b}-s_{t}^{b^{-}} \leq y_{t k}^{b} \\
1-\frac{1}{t_{1}+t_{2}}\left(\sum_{t=1}^{t_{1}} \frac{s_{t}^{g^{+}}}{y_{t k}^{g}}+\sum_{t=1}^{t_{2}} \frac{s_{t}^{b^{-}}}{y_{t k}^{b}}\right)>0 \\
s^{-}>0, s^{b}>0, s^{g}>0, \lambda>0 \\
i=1,2, \mathrm{~L}, \quad m ; t=1,2, \mathrm{~L}, q ; j=1,2, \mathrm{~L}, n(j \neq k)
\end{array}\right.
\end{aligned}
$$

Where ${ }^{\lambda}$ is the weight vector, ${ }^{x_{i j}}$ is the j-th input of the $\mathrm{i}$-th decision-making unit; $y_{i}$ is the $\mathrm{j}$-th output of the $\mathrm{t}$-th decision-making unit; $k$ is the evaluated unit; $\overline{s^{-}}$is excessive input; $s^{g}$ is insufficient expected output; $s^{b}$ is

\footnotetext{
* Corresponding author: Xieheng4964@163.com
} 
excessive unexpected output. In the formula, the numerator and denominator of ${ }^{\rho}$ respectively represent the average reducible ratio and average expandable ratio of actual input and actual output of production decisionmaking unit relative to production frontier, and respectively represent input inefficiency and production inefficiency. When $\rho<1$, it indicates that the $D M U$ is in invalid state; when $\rho \geq 1$, it indicates that the $D M U$ is effective.

\subsection{Index selection and data sources}

This study covers the green water resources efficiency of Beijing, Tianjin and 11 prefecture level cities in Hebei Province from 2008 to 2018, and the indicators are divided into input-oriented and output-oriented. In order to actively respond to the concept of national green development, this paper establishes six evaluation indexes on the basis of considering the sustainable development of economy, society and environment. The input-oriented indicators include natural resources, capital and labor, which are urban water consumption, capital stock and labor input; the output-oriented indicators include economic, social development and environmental output, which are Gross Regional Product (GRP), human sustainable development index (SDI) and sewage discharge. The specific indicators are as follows:

Table 1. SBM index of green water resources efficiency in Jing-Jin-Ji

\begin{tabular}{lccc}
\hline $\begin{array}{l}\text { Index } \\
\text { type }\end{array}$ & variable & Definition & Company \\
\hline & $\begin{array}{c}\text { Input of } \\
\text { natural } \\
\text { resources } \\
\text { index }\end{array}$ & $\begin{array}{c}\text { Total water } \\
\text { consumption }\end{array}$ & $\begin{array}{c}\text { Billion cubic } \\
\text { meters }\end{array}$ \\
& $\begin{array}{c}\text { Capital } \\
\text { investment }\end{array}$ & Capital stock & RMB100mn
\end{tabular}

\begin{tabular}{|c|c|c|c|}
\hline & Labor input & $\begin{array}{l}\text { Number of } \\
\text { employees }\end{array}$ & $\begin{array}{l}\text { ten thousand } \\
\text { people }\end{array}$ \\
\hline \multirow{3}{*}{$\begin{array}{l}\text { Output } \\
\text { index }\end{array}$} & $\begin{array}{c}\text { Economic } \\
\text { output }\end{array}$ & GRP & RMB100mn \\
\hline & Social output & SDI index & $\%$ \\
\hline & $\begin{array}{c}\text { Environment } \\
\text { al output }\end{array}$ & $\begin{array}{l}\text { Sewage } \\
\text { discharge }\end{array}$ & 10000 tons \\
\hline
\end{tabular}

Note: the data are from China City Yearbook, China Statistical Yearbook and statistical bulletin of each city

\section{Result Analysis}

\subsection{Analysis of green water resources efficiency of provinces and cities based on super SBM model}

Using the above super SBM model considering the unexpected output, the green water resources efficiency of 13 cities in Beijing, Tianjin and Hebei in 2013-2018 is calculated. The measurement results are shown in Table 3. The efficiency value can reflect the green water resources efficiency level of Beijing, Tianjin and Hebei as a whole and each city. Generally speaking, the efficiency of green water resources in Beijing, Tianjin and Hebei cities has not reached the DEA effective state, and there is still much room for improvement. Horizontally, the green water resource efficiency of Jing-Jin-Ji generally fluctuated around 0.850 from 2013 to 2018, fluctuated and increased from 2013 to 2015, reached the peak in 2015, and showed an obvious downward trend from 2016 to 2018 . It shows that the efficiency of green water resources in Beijing Tianjin Hebei region is generally good, but the effect is lack of stability. From the vertical point of view, there is a large regional difference, the best area is 1.334 , but the most efficient area is only 0.385 , which needs to improve the spatial distribution of water resources.

Table 2. green water resources efficiency of Jing-Jin-Ji from 2013 to 2018

\begin{tabular}{ccccccccc}
\hline Year & $\mathbf{2 0 1 3}$ & $\mathbf{2 0 1 4}$ & $\mathbf{2 0 1 5}$ & $\mathbf{2 0 1 6}$ & $\mathbf{2 0 1 7}$ & $\mathbf{2 0 1 8}$ & AVG & Rank \\
\hline Beijing & 1.270 & 1.299 & 1.352 & 1.432 & 1.364 & 1.392 & 1.352 & 1 \\
Tianjin & 1.127 & 1.218 & 1.208 & 1.145 & 1.070 & 1.035 & 1.134 & 4 \\
Shijiazhuang & 1.118 & 1.075 & 1.170 & 1.277 & 0.942 & 0.670 & 1.042 & 6 \\
Chengde & 1.254 & 1.145 & 1.200 & 1.300 & 1.210 & 1.222 & 1.221 & 3 \\
Zhangjiakou & 0.556 & 1.008 & 1.005 & 1.075 & 1.032 & 1.024 & 0.950 & 7 \\
Qinhuangdao & 1.340 & 1.338 & 1.224 & 1.271 & 1.380 & 1.412 & 1.328 & 2 \\
Tangshan & 1.090 & 1.091 & 1.078 & 1.024 & 1.138 & 1.160 & 1.097 & 5 \\
Langfang & 0.424 & 0.539 & 1.006 & 0.571 & 0.338 & 0.392 & 0.545 & 11 \\
Baoding & 0.454 & 0.637 & 0.791 & 0.560 & 0.496 & 0.477 & 0.569 & 9 \\
Cangzhou & 0.611 & 0.711 & 0.703 & 0.677 & 0.619 & 0.574 & 0.649 & 8 \\
Hengshui & 0.621 & 0.513 & 0.652 & 0.678 & 0.356 & 0.413 & 0.539 & 10 \\
Xingtai & 0.494 & 0.532 & 0.530 & 0.476 & 0.449 & 0.466 & 0.491 & 12 \\
Handan & 0.423 & 0.417 & 0.468 & 0.316 & 0.262 & 0.266 & 0.359 & 13 \\
Hebei & 0.762 & 0.819 & 0.894 & 0.839 & 0.747 & 0.734 & 0.799 & - \\
AVG & 0.829 & 0.886 & 0.953 & 0.908 & 0.820 & 0.808 & - & - \\
\hline
\end{tabular}


From the perspective of Beijing, Tianjin and Hebei, the overall green water efficiency of Hebei Province is 0.799 , which is still far behind the average efficiency of Beijing (1.352) and Tianjin (1.134). There are many factors leading to the development of the average green water resources efficiency in three provinces. From the perspective of input-output scale in 2018, the capital and water resources input of Hebei Province is much higher than that of Beijing and Tianjin, and the economic output level is relatively high, but the output of social development index is lower than that of Beijing and Tianjin. The social development index of Hebei Province in 2018 is 24.95, and that of Tianjin is 57.98. Beijing is more than three times that of Hebei Province, but the level of unintended output is far higher than that of Beijing and Tianjin. In 2018, the wastewater discharge of Hebei Province is 2.789 billion tons, twice that of Beijing and three times that of Tianjin. Therefore, there are serious problems of input and unintended output redundancy in Hebei Province. which makes the overall efficiency of green water resources in Hebei Province is lower than that in Beijing and Tianjin; From the perspective of industrial structure, Hebei Province is mainly dominated by traditional manufacturing and agriculture, the water resources utilization system is not perfect, and the extensive development mode makes it more difficult for Hebei Province to implement the green transformation and upgrading of water resources. The proportion of the tertiary industry in Beijing far exceeds that of the primary and secondary industries, and continues to occupy a super dominant position. Compared with the primary and secondary industries, the tertiary industry has the characteristics of high technology, low energy consumption and low pollution, which can promote the efficiency of green water resources. The efficiency level of green water resources in Tianjin is higher than that in Hebei Province, but there is still a gap compared with Beijing. The reason lies in the rapid economic development of Tianjin, at the same time, the problems are more and more prominent, the industrial structure is unreasonable, the problem of water pollution is serious, and the pressure of water resources supply in Tianjin increases with the increase of population. Therefore, it is necessary for Tianjin to slow down the speed of economic development in order to promote the green development of water resources.

From the urban level, Beijing, Qinhuangdao and Chengde are in a high level of green water efficiency, reaching more than 1.2, while Tianjin, Tangshan and Shijiazhuang are also in an effective state of efficiency, but the reasons for each city are different. As the capital of China, Beijing has sufficient capital and energy input, and its expected output is much higher than other cities. The efficiency of green water resources in Tianjin is at a high level, but there is still a gap with Beijing, Qinhuangdao and Chengde. The main reason is that Tianjin's water resources are unevenly distributed in time and space, and there is a significant gap between flood season and non flood season, which leads to a greater pressure on Tianjin's water resources. In addition, with the rapid economic and social development in recent years, Tianjin has become a super large city ${ }^{[2]}$, attracting a large number of talents and capital, and the agglomeration of population has also brought a greater burden on Tianjin's water resources; Qinhuangdao, Chengde, Tangshan and Shijiazhuang, have a gap with Beijing and Tianjin in terms of economic scale, capital, energy input and expected output. Qinhuangdao is located in the coastal area with rapid development of urban service industry and little damage to the water body. In addition, Qinhuangdao is in a low gradient in water resources input. The annual average water resources consumption of Qinhuangdao is 535 million cubic meters, only 1 / 7 of Beijing's annual water resources consumption, while the social development index is more than half of Beijing's, therefore, the proportion of high-quality population and the proportion of science and education expenditure in the total financial expenditure have great advantages; Chengde is located in the upper reaches of Jing-Jin-Ji. There are four water systems in Chengde, namely Luanhe River, chaobaiji canal, Liaohe River and Dalinghe river. The water quality is excellent and the water quantity is abundant, so the efficiency of green water resources is in an effective state for a long time. The efficiency of green water resources in Tangshan is mainly due to the high efficiency of water use Haixia et al.$^{[3]}$ found that the comprehensive water use efficiency of Tangshan City reached an effective state, and its agricultural water use efficiency was at a high level; the green water resource efficiency of Shijiazhuang City fluctuated greatly, with a peak value of 1.277 , and a trough value of 0.670 . How to keep the green water resource efficiency level in a stable state is the primary task of Shijiazhuang city.

Zhangjiakou, Hengshui, Cangzhou, Baoding, Xingtai, Handan, Langfang and other places have not yet reached the effective state of green water resources efficiency. Although Zhangjiakou City ranks seventh, there is still a big gap with Shijiazhuang, which ranks sixth. The green water resource efficiency of Hengshui have been greatly reduced from 2013 to 2018 , which is directly related to Hengshui's undertaking of Beijing's non capital functions, with the transfer of industries in Beijing, the input of fixed assets in Hengshui City has increased by multiple, and the output growth rate is far less than the input growth rate, which leads to the reduction of the efficiency of green water resources; the agricultural water consumption of Cangzhou and Baoding is about 6 times of that of Qinhuangdao, so it is necessary to improve the industrial structure of the two places and enhance the efficiency of agricultural water use. Langfang area is relatively short of water resources, and its industries are mostly furniture making and biomedicine, which makes the fixed capital and water resources input larger, but the economic output is relatively low. Xingtai and Handan are located in the lower reaches of Jing-Jin-Ji geographically. The lack of regional advantages leads to the low efficiency of green water resources for a long time.

\subsection{Analysis of spatial and temporal differences of green water resources efficiency}

In order to further explore the spatial and temporal differences of green water resources efficiency in Jing-Jin$\mathrm{Ji}$, The north of Beijing is defined as the upper reaches of 
Jing-Jin-Ji, and the south of Beijing is defined as the lower reaches of Jing-Jin-Ji. It can be seen that the imbalance of green water resources efficiency in Jing-Jin-Ji has not improved significantly over time. The green water resources efficiency in the upper reaches has always remained at a high level, and the lower reaches has remained at a low level. In the upstream area, Beijing, Langfang and Qinhuangdao have been in a state of high efficiency, Tianjin and Tangshan have been in a state of medium efficiency, Zhangjiakou was in a state of low efficiency in 2013, but it rose sharply in 2014 and maintained in a state of high efficiency. The efficiency of green water resources in Beijing is the highest in the region. As a national science and technology innovation center, the upgrading of science and technology has gradually rationalized the utilization of water resources. In addition, in recent years, Beijing has actively promoted the concept of ecological civilization and green development, increased investment in pollution control and environmental management, resulting in the green water resources efficiency always ahead of other cities in Beijing, Tianjin and Hebei. The efficiency of green water resources in Qinhuangdao and Chengde has always been maintained at a high level, which is better than that in Tianjin. This shows that the level of green water resources efficiency in a region is not necessarily related to the economic level ${ }^{[4]}$, and the efficiency reaching an effective state only indicates that the input and output matching of the region is better. In 2014, the efficiency of green water resources in Zhangiiakou rapidly increased to an effective state, mainly because Zhangjiakou City has a higher expected output (sustainable development index) after 2014, which shows that the regional green development has achieved initial results.

In the downstream areas, Hengshui, Cangzhou and Shijiazhuang are better than other areas, but they all show a downward trend in varying degrees. The efficiency of green water resources in Shijiazhuang was stable at first and then decreased. The efficiency of Hengshui has been greatly reduced, from the high efficiency level in 2013 to the low efficiency level in 2018. Cangzhou has been floating between medium efficiency and low efficiency. The efficiency of green water resources in the other four cities has been at a low level. Although the efficiency of green water resources in Shijiazhuang shows an improvement trend, it is still in a fluctuating state, which indicates that the industrial transformation and upgrading has made the utilization of water resources in Shijiazhuang more reasonable, but the effect remains to be strengthened; the efficiency of green water resources in Hengshui has decreased from 0.621 in 2013 to 0.413 in 2018, This is directly related to Hengshui's undertaking of Beijing's non capital functions. With the transfer of Beijing's industries, Hengshui's fixed assets investment has increased by multiple, and the output growth rate is far less than the input growth rate. Baoding, Xingtai and Handan have been in the low efficiency area of green water resources for a long time. The reason is that they are all located in the lower reaches of Jing-Jin-Ji. Water pollution has seriously damaged the water quality of the lower reaches, making the water resources which were in short supply more tense. Therefore, it is urgent to improve the regional water use structure, further accelerate the industrial transformation, promote the transfer and upgrading of industrial structure, develop and expand the energy-saving and environmental protection industry, improve the ability of environmental protection technology research and development, and realize the green manufacturing industry.

\section{4 conclusion}

Based on the concept of ecological optimization and green development, this paper uses super efficiency SBM model to measure the green water resources efficiency of 13 cities in Jing-Jin-Ji from 2013 to 2018, and analyzes their spatial and temporal differences. Research shows:

(1) During the study period, the overall level of green water resources efficiency of Jing-Jin-Ji is high, but there are significant differences among regions, and the spatial distribution of green water resources efficiency is uneven. The order of the average green water resources efficiency of the three provinces and cities is Beijing $>$ Tianjin $>$ Hebei. There is a big gap in the efficiency of green water resources among the 13 cities in Jing-Jin-Ji, The average value of Beijing with the highest green water efficiency is 1.316, while Handan with the lowest green water efficiency is only 0.429 .

(2) From the perspective of temporal and spatial differences, the efficiency of green water resources in Beijing Tianjin Hebei region fluctuates with time, and the regional differences are obvious. The upward trend is mainly in the upstream region, while the efficiency of green water resources in some downstream cities, such as Hengshui and Shijiazhuang, decreases significantly, and the rest of the region is stable at a low level, forming a regional green water resources efficiency "upstream $>$ downstream" pattern.

\section{References:}

1. Zhang F, Chen YG, Liu P. Study on the spatial and temporal relationship between urban system and water system structure in Beijing Tianjin Hebei [J]. Progress of geographical science, 2020,39 (03): 377 388

2. Yan DZ, song BK, Wen J, Zhen MZ, Li SQ, Li ZL. Sustainable development strategy of water resources and water environment in Tianjin [J]. Environmental protection, 2019,47 (14): 47-51

3. Hai X, Li WF, Zhou WQ, Han LJ, Qian YG. Water use efficiency of Beijing Tianjin Hebei Urban Agglomeration and its relationship with urbanization level [J]. Acta ecologica Sinica, 2018,38 (12): 42454256

4. Sun CZ, Jiang K, Zhao LS. Efficiency measurement and spatial pattern of green water resources in China [J]. Journal of natural resources, 2017,32 (12): 1999 